\title{
The Effect of Captopril on Urinary Protein Excretion in Puromycin Aminonucleoside Nephrosis in Rats
}

\author{
HOWARD TRACHTMAN, BETH ZAVILOWITZ, BOYCE BENNETT, AND DAVID I. GOLDSMITH \\ Departments of Pediatrics (Division of Pediatric Nephrology) and Pathology, Albert Einstein College of Medicine, \\ Bronx, New York 10461
}

\begin{abstract}
We investigated the effect of captopril, an orally active angiotensin converting enzyme inhibitor, on urinary protein excretion in puromycin aminonucleoside nephrotic rats. The administration of captopril $(10 \mathrm{mg} / 100$ $\mathrm{g}$ body weight) decreased proteinuria on days 10-14 following the administration of puromycin aminonucleoside (73.0 versus $125.0 \mathrm{mg}, p<0.01$, without affecting glomerular filtration rate. The beneficial effect of captopril was not abolished by the continuous intravenous infusion of angiotensin II (10 $\mu \mathrm{g} / \mathrm{kg} / \mathrm{h}$ for 9 days) or subcutaneous injections of aprotinin (50,000 KIU/day for 3 days). Indomethacin, in moderate $(5 \mathrm{mg} / \mathrm{kg} /$ day for 3 days $)$ or high $(10 \mathrm{mg} /$ $\mathrm{kg} /$ day) doses, abolished the captopril attenuation in urinary protein excretion. The salutory effect of captopril was characteized by a reduction in the fractional excretion of protein without compromising the glomerular filtration rate. No difference in renal ultrastructure was noted in captopril-treated versus control animals. Captopril was ineffective in reducing urinary protein excretion in rats with adriamycin-induced glomerulopathy. We conclude that captopril acts to reduce proteinuria in renal disease states arising from depletion of the glomerular basement membrane polyanion. The mechanism of action is postulated to be an alteration in renal hemodynamics, namely increased blood flow and a decrease in the ultrafiltration coefficient, that are the consequence of increased intrarenal prostaglandin production. (Pediatr Res 19: 828-834, 1985)
\end{abstract}

\section{Abbreviations}
AI, angiotensin I
AII, angiotensin II
ACE, angiotensin converting enzyme
BW, body weight
FEpr, fractional excretion of protein
GBM, glomerular basement membrane
GFR, glomerular filtration rate
$\mathbf{k}_{\mathrm{f}}$, ultrafiltration coefficient
PAN, puromycin aminonucleoside
$Q_{A}$, renal blood flow

Many vasoactive substances are capable of altering quantitative urinary protein excretion in normal and disease states. The

Received November 19, 1984; accepted March 26, 1985

Reprint requests Howard Trachtman, M.D., Downstate Medical Center, Department of Pediatrics, Box no. 49, 450 Clarkson Avenue, Brooklyn, NY 11203.

Presented in part at the annual meeting of the Society for Pediatric Research May 3, 1983 (Pediatr Res 17:359A, 1983). short-term infusion of AII into normal animals causes an increase in the fractional and absolute excretion of protein, provided the GFR is preserved $(1-3)$. In contrast, indomethacin administration to patients with the nephrotic syndrome results in a parallel decline in absolute urinary protein excretion and GFR $(4,5)$.

Captopril, an orally active ACE inhibitor, interacts with several important hormonal systems that control intrarenal hemodynamics (6). By virtue of its capacity to act as a converting enzyme inhibitor, this drug interferes with the conversion of AI to AII Under the name kininase II, this same dipeptidase is responsible for the proteolytic inactivation of bradykinin, causing elevated blood kinin concentrations and increased urinary kinin excretion (7). Captopril also acts, either directly or indirectly, to stimulate intrarenal prostaglandin synthesis and release. Each of these alterations, singly or in combination, might affect renal hemodynamic factors or intrinsic permselectivity properties of the glomerular capillary that influence macromolecular clearance $(8$, 9). We, therefore sought to determine whether captopril could modify the degree of proteinuria observed in nephrotic rats and, if so, to elucidate its mechanism of action.

\section{METHODS}

Male Sprague-Dawley rats, weighing $125-275 \mathrm{~g}$, were paired by weight and maintained in individual metabolic cages. They were fed ad libitum a diet of standard laboratory rat food. After a period of acclimatization to these conditions, 24-h urine samples were collected for 4 days to establish the baseline urinary protein and creatinine excretion rates. On day 5 , both animals in each pair received a single intraperitoneal injection of PAN (Sigma Chemical Co., St. Louis, MO) $15 \mathrm{mg} / 100 \mathrm{~g} \mathrm{BW}$ dissolved in $0.15 \mathrm{M}$ saline. Immediately after the administration of PAN, animals randomly assigned to the experimental group were started on captopril. The daily dose was $10 \mathrm{mg} / 100 \mathrm{~g} \mathrm{BW}$ dissolved in $0.15 \mathrm{M}$ saline and administered by oral gavage. Control animals received an equal volume of saline vehicle by the same route. Five successive protocols were performed and are described below (Fig. 1)

Protocol $I$ ( $n=9$ pairs): no additional drugs were administered. The duration of study was 10 days following PAN administration.

Protocol II $(n=5$ pairs): all animals received a continuous infusion of AII (Sigma), $10 \mu \mathrm{g} / 100 \mathrm{~g} \mathrm{BW} / \mathrm{h}$, via intraperitoneally implanted osmotic minipumps (Alzet, Inc., Palo Alto, CA). The infusion commenced on day 6 ( 1 day post-PAN administration) and was maintained for 9 days.

Protocol III ( $n=5$ pairs): all animals received aprotinin (Sigma) dissolved in a 5\% dextrose solution, 50,000 kallikrein inhibitory units daily, administered subcutaneously in two divided doses (10). The animals were studied for 7 days after the administration of PAN; aprotinin was given on the final 3 days. 


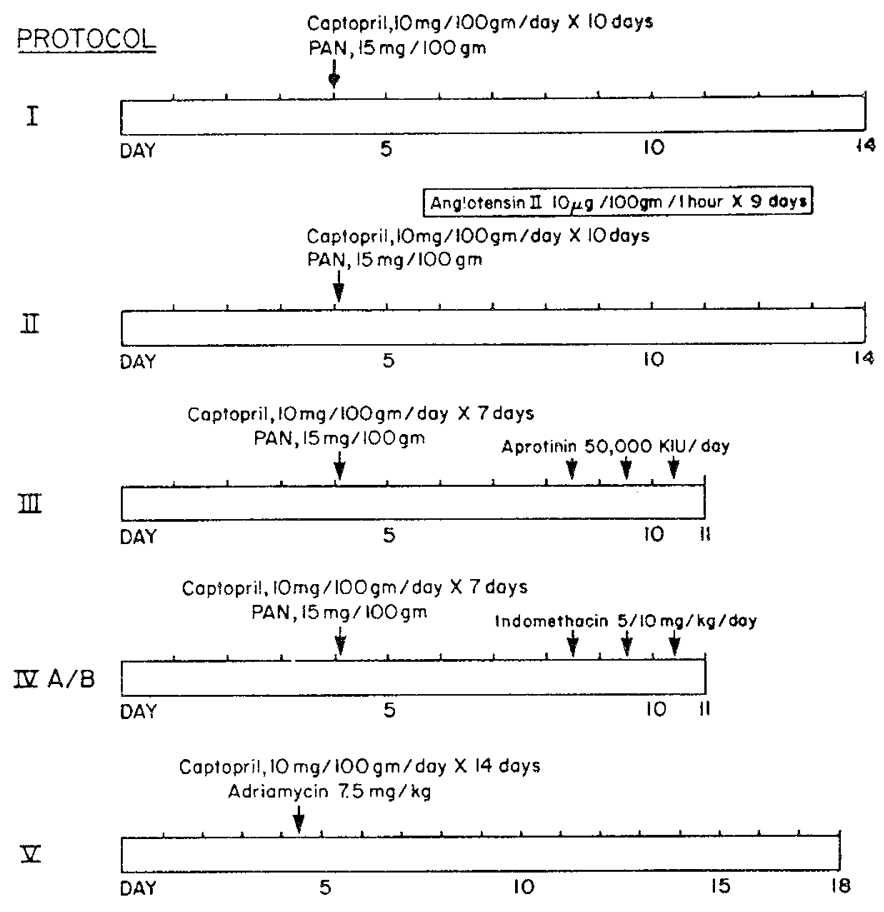

Fig. 1. Graphic illustration of the experimental design used in protocols $\mathrm{I}-\mathrm{V}$.

Protocol IVA ( $n=5$ pairs): all animals received indomethacin (Merck, Sharp \& Dohme, West Point, PA), dissolved in TRIS$\mathrm{HCl}$ buffer $(\mathrm{pH} 8), 5 \mathrm{mg} / \mathrm{kg} \mathrm{BW}$ as a loading dose and then 5 $\mathrm{mg} / \mathrm{kg} \mathrm{BW} /$ day, administered intraperitoneally in two divided doses. The animals were studied for 7 days following the administration of PAN; indomethacin was given on the final 3 days.

Protocol IVB ( $n=5$ pairs): all animals received indomethacin dissolved in TRIS-HCl buffer ( $\mathrm{pH} 8$ ), $10 \mathrm{mg} / \mathrm{kg} \mathrm{BW}$ as a loading dose and then $10 \mathrm{mg} / \mathrm{kg} \mathrm{BW} /$ day administered intraperitoneally in two divided doses. The animals were studied for 7 days after the administration of PAN; indomethacin was given on the final 3 days.

Protocol $V(n=4$ pairs): nephrosis was induced by the intravenous administration of a single dose of adriamycin (Adria Laboratories Inc., Columbus, $\mathrm{OH}) 7.5 \mathrm{mg} / \mathrm{kg}$ BW. Experimental animals received captopril, $10 \mathrm{mg} / 100 \mathrm{mg} \mathrm{BW} /$ day by gavage, while control animals were given an equal volume of saline vehicle. No additional drugs were administered to these animals. The animals were studied for 14 days after the intravenous infusion of adriamycin.

The animals were weighed and 24-h urine samples were collected daily for the duration of each protocol. Measurements of urinary protein and creatinine excretion were made on each sample. On the final day of study, the rats were sacrificed using pentobarbital anaesthesia, $50 \mathrm{mg} / \mathrm{kg} \mathrm{BW}$, given intraperitoneally. Serum samples were obtained for the determination of albumin and creatinine concentration. The kidneys were rapidly excised and portions placed in Dubosq-Brazil and cacodylate-buffered $2.5 \%$ glutaraldehyde solutions for fixation for light and electron microscopic examination, respectively. Thin sections were cut from paraffin-embedded material and stained with hematoxylin and eosin, periodic acid-Schiff, and Masson trichrome methods for light microscopy. Portions of the tissue for electron microscopy were postfixed in osmium tetroxide and stained with lead citrate and uranyl acetate. Ultrathin sections were cut from plastic embedded material and viewed with an electron microscope. Renal histological specimens were examined by a single pathologist (B.B.) who was blinded as to the protocol and experimental assignment of each animal.

Serum and urinary protein concentrations were determined spectrophotometrically (Guilford model) following sulfosalicylic acid precipitation (11). Serum and urinary sodium and potassium concentrations were measured with a flame photometer with lithium as an internal standard. Serum and urinary creatinine concentrations were measured using the Jaffe reaction (12).

The endogenous creatinine clerance was assumed to be equivalent to the GFR. The FEpr and creatinine clearance were calculated using standard formulas.

Statistical comparisons between experimental and control groups within each protocol were made using Student's paired $t$ test. Multiple comparisons between groups were made using the Duncan multiple range test and an anlysis of variance. Results were considered statistically significant if $p<0.05$.

\section{RESULTS}

The mean weight gain of the experimental and control animals was similar in all of the study protocols except in protocol III, in which captopril-treated animals gained more weight than controls $(p<0.01)$ (table 1$)$. All animals became visibly edematous and developed moderate to marked degrees of ascites within 7 days of receiving PAN. No measurements of serum total protein, albumin, or cholesterol were made. Daily urine output and fluid intake tended to rise in parallel with the appearance of sustained heavy proteinuria in all animals studied. Each animal manifested at least a 2-fold rise above its baseline daily urinary protein excretory rate following the administration of PAN.

The results in protocol I are illustrated graphically in Figure 2, in which mean daily protein excretion is plotted versus day. There was no significant change in the mean daily urinary excretion during the first 3 days after the administration of PAN in either the control or experimental groups. However, on day 8 there was an abrupt onset of proteinuria in both groups. Thereafter, the mean daily protein excretion was significantly reduced on days $10-14$ in the rats given captopril compared to their untreated counterparts $(p<0.01)$.

The results obtained in protocol II and III are illustrated in Figures 3 and 4 . All of the animals that received the infusion of pharmacologic doses of AII demonstrated a rise in proteinuria 1 day earlier (day 7) than the animals studied in protocol $\mathrm{I}$. This discrepancy is a consequence of the All-induced enhancement in the fractional and absolute excretion of macromolecules (2). Thereafter, on days 9-13 experimental animals given captopril displayed a significant attenuation in protein excretion compared to control rats $(p<0.05)$. A similar reduction in proteinuria was observed on days $8-11(p<0.01)$ in experimental versus control rats given aprotinin. These observations imply that captopril attenuation of proteinuria in PAN-nephrotic rats is not mediated via a reduction in the circulating levels of AII or a potentiation of intrarenal bradykinin activity.

The results obtained in protocols IVA and IVB are illustrated

Table 1. Initial and final body wt of control and experimenta! animals in protocols $I-V$

\begin{tabular}{|c|c|c|c|c|}
\hline \multirow[b]{2}{*}{ Protocol } & \multicolumn{2}{|c|}{ Initial wt } & \multicolumn{2}{|c|}{ Final wt } \\
\hline & $\mathrm{C}^{*}$ & $E^{*}$ & $\mathrm{C}$ & $E$ \\
\hline \multirow[t]{2}{*}{$I$} & 169.1 & 185.0 & 236.6 & 246.7 \\
\hline & \pm 12.9 & \pm 21.5 & \pm 25.3 & \pm 23.9 \\
\hline \multirow[t]{2}{*}{ II } & 140.8 & 138.8 & 168.6 & 151.6 \\
\hline & \pm 5.2 & \pm 4.1 & \pm 13.9 & \pm 14.9 \\
\hline \multirow[t]{2}{*}{ III } & 177.8 & 181.8 & 223.6 & $257.4 \dagger$ \\
\hline & \pm 2.5 & \pm 4.8 & \pm 5.8 & \pm 9.0 \\
\hline \multirow[t]{2}{*}{ IVA } & 156.9 & 159.6 & 196.6 & 192.0 \\
\hline & \pm 9.7 & \pm 9.3 & \pm 8.3 & \pm 10.5 \\
\hline \multirow[t]{2}{*}{ IVB } & 166.4 & 169.4 & 181.0 & 177.2 \\
\hline & \pm 4.3 & \pm 7.5 & \pm 7.3 & \pm 10.9 \\
\hline \multirow[t]{2}{*}{ V } & 255.0 & 253.3 & 280.0 & 304.3 \\
\hline & \pm 10.6 & \pm 10.6 & \pm 9.8 & \pm 13.3 \\
\hline
\end{tabular}

${ }^{*} \mathrm{C}$, control (vehicle); E, experimental (captopril).

Values reported as mean $\pm \mathrm{SEM} ; \dagger p<0.01$. 


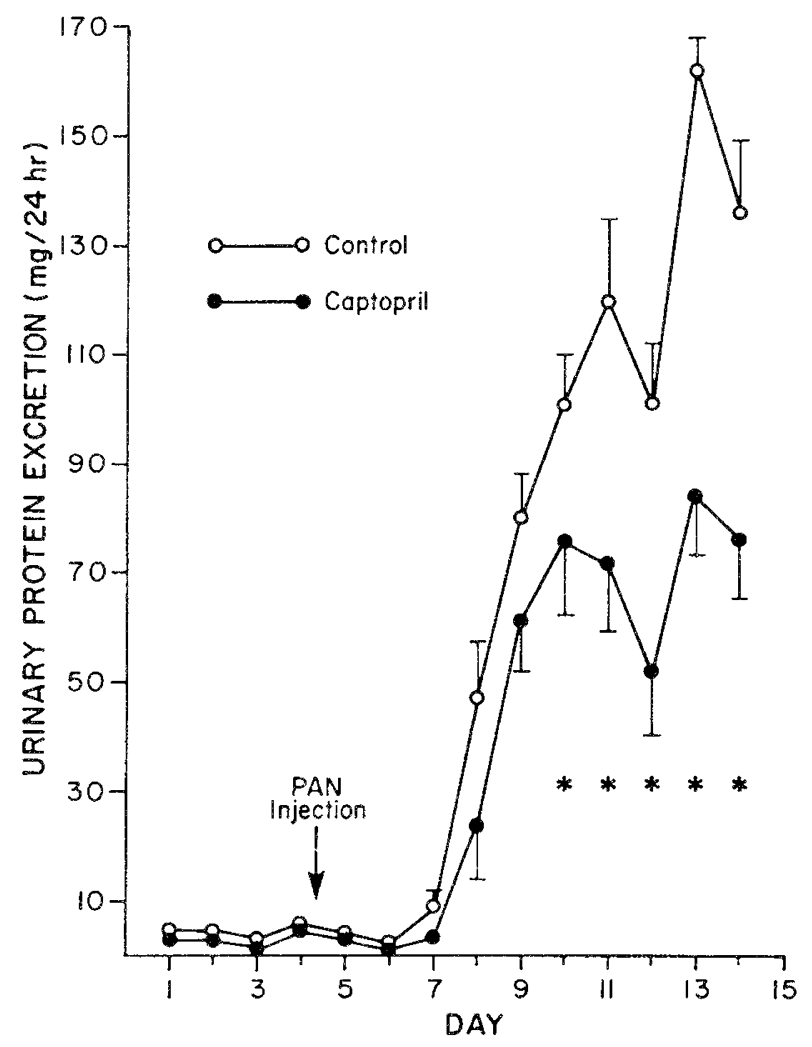

Fig. 2. Urinary protein excretion plotted versus day in animals treated according to protocol $\mathrm{I}$. Values are given as mean $\pm \mathrm{SEM} ;{ }^{*} p<0.01$.

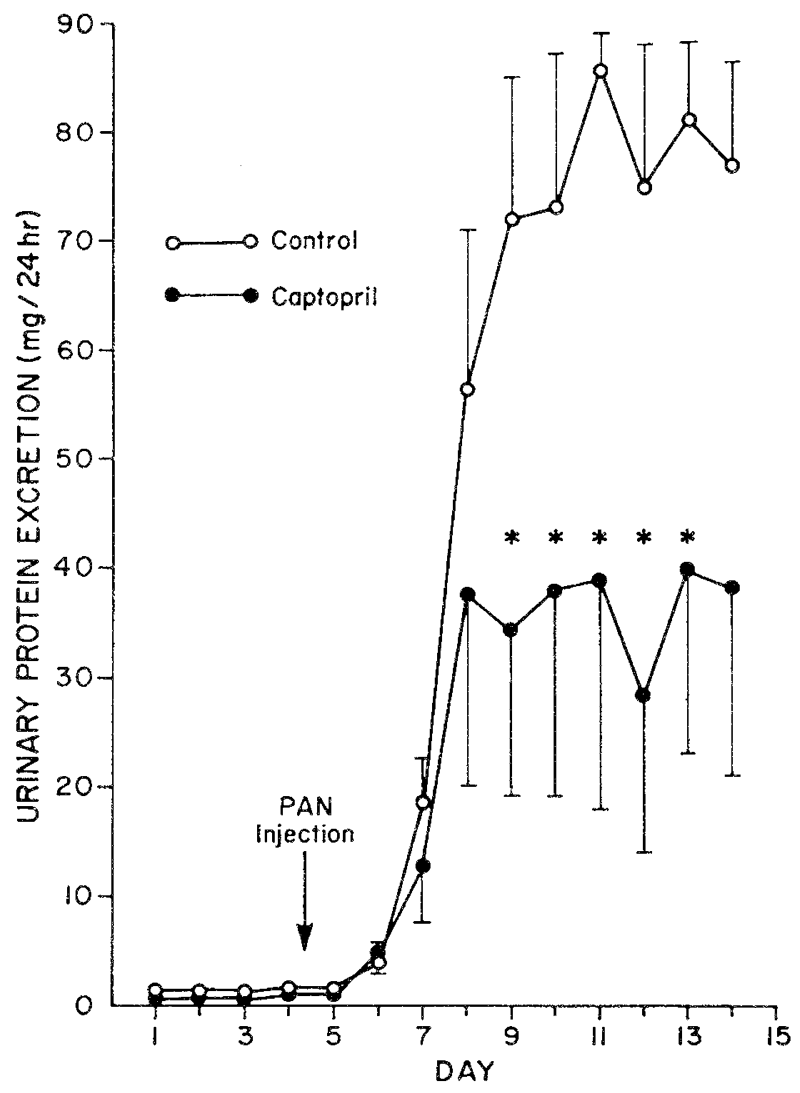

Fig. 3. Urinary protein excretion plotted versus day in animals treated according to protocol II. Values are given as mean \pm SEM; ${ }^{*} p<0.05$.

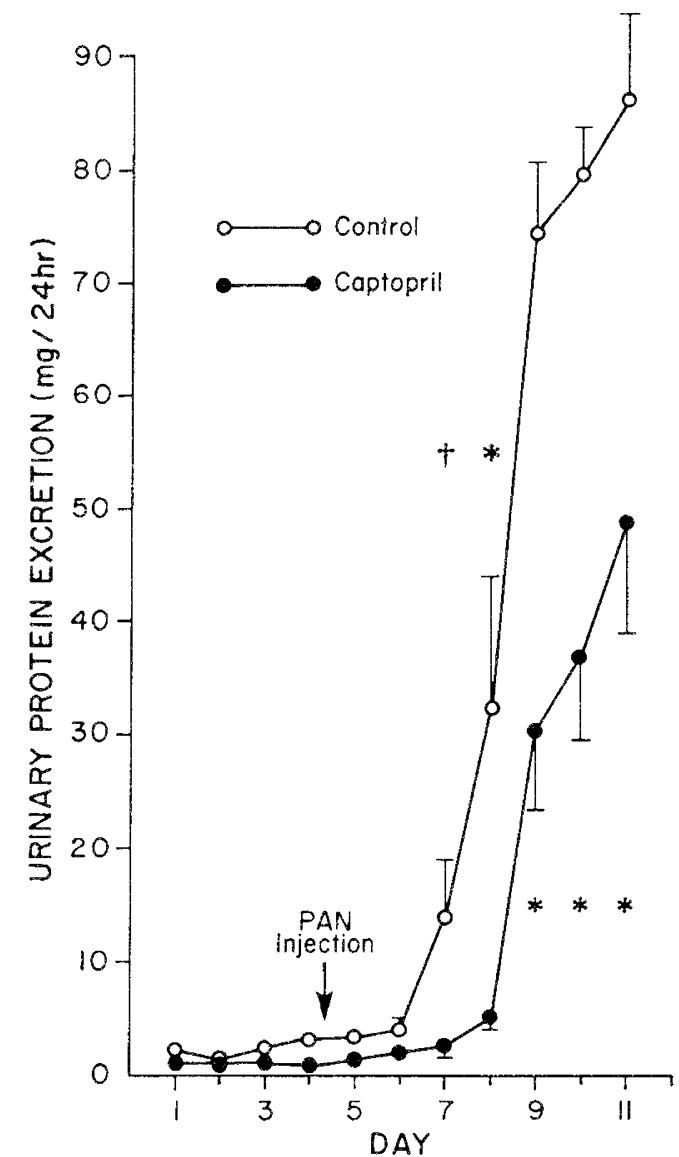

Fig. 4. Urinary protein excretion plotted versus day in animals treated according to protocol III. Values are given as mean $\pm \mathrm{SEM} ;{ }^{*} p<0.01$, $+p<0.05$.

in Figure 5. In both studies, there was a rise in mean daily protein excretion on day 8, 4 days after PAN administration in experimental and control animals. However, on both the moderate and high dose indomethacin regimens, no significant differences in the daily excretion of protein were noted on days $9-11$ between experimental and control animals. Thus, systemic treatment with a prostaglandin synthesis inhibitor abolished any difference in mean daily urinary protein excretion between the two treatment groups.

Animals given adriamycin to induce proteinuria demonstrated a gradual rise in urinary total protein excretion that was initially detected on day 5 after the intravenous injection and reaching a peak value by day 11 . At no time during the 2-wk period of observation were any significant differences in mean daily protein excretion noted between captopril-treated and control animals (day 18: $144.9 \pm 8.3 \mathrm{mg} / 24 \mathrm{~h}$ captopril versus $169.3 \pm 7.2$ control).

The data obtained on the final day of study in each protocol namely, mean protein excretion, GFR, and $\mathrm{FE}_{\mathrm{pr}}$ are presented in Table 2 . The mean urinary protein excretion on the final day of study in the experimental and control animals reflected the pattern that had been established during the preceding 3-5 days within each protocol. There was no significant difference in the mean value for GFR between the captopril-treated and control animals in any drug treament group. The serum creatinine concentrations in experimental and control rats paralleled the respective GFR determinations (Table 2). The administration of indomethacin, $10 \mathrm{mg} / \mathrm{kg} \mathrm{BW} /$ day, resulted in a substantial reduction in the GFR in both groups of animals $(0.21 \pm 0.04 \mathrm{ml} /$ min, captopril-treated versus $0.39 \pm 0.07$, control) compared to the values observed in the other protocols $(p<0.05)$. When the 
daily protein excretion on the final day of the study was correlated with the individual values for GFR in the animals studies in protocol I, the $r$ value was -0.62 and +0.62 in captopriltreated and control animals, respectively $(p<0.05)$ (Fig. 6). The magnitude and direction of the correlation coefficients changed in an analogous fashion in protocols II and III, although the changes were not statistically significant in either instance. In marked contrast, in protocol IVA the correlation coefficients were +0.76 and +0.69 in experimental and control animals, respectively, while in protocol IVB the values were +0.67 and +0.71 (Fig. 6). Using an analysis of variance, the differences in the correlation coefficients observed in protocols I and IV were statistically significant; no other comparisons were significantly different.

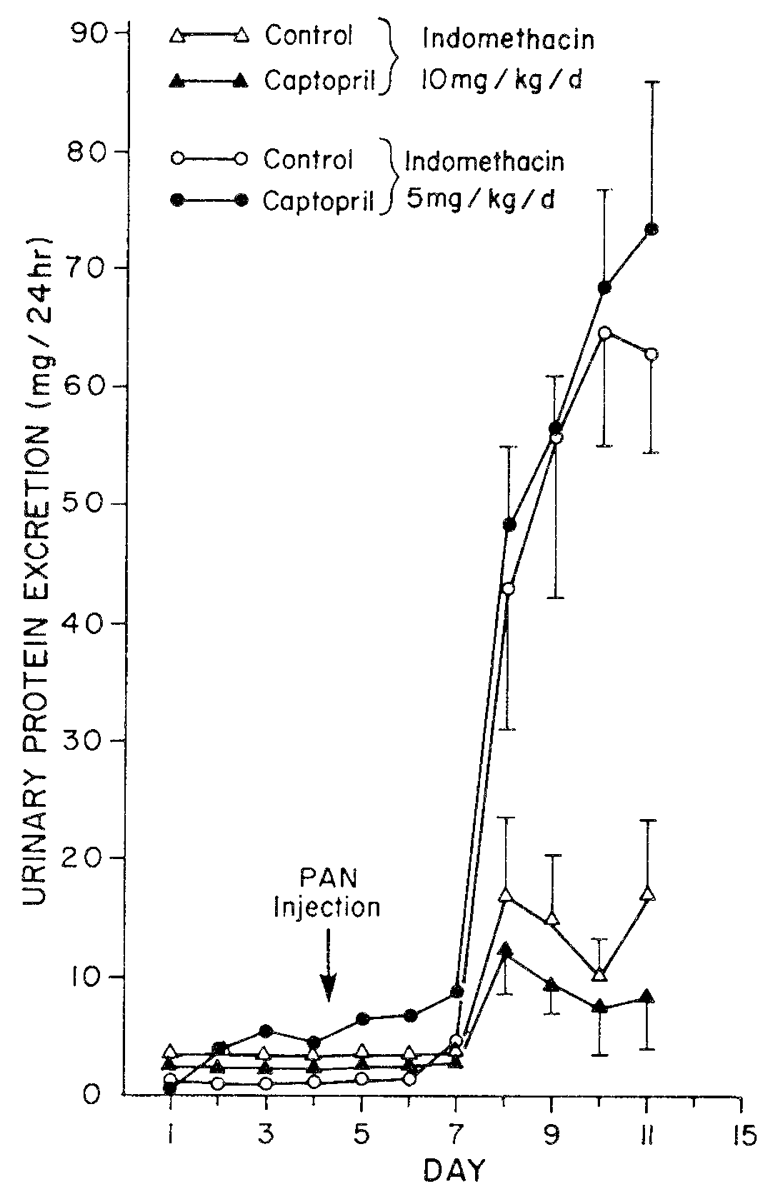

Fig. 5. Urinary protein excretion plotted versus day in animals treated according to protocols IVA and IVB. Circles indicate animals given indomethacin, $5 \mathrm{mg} / \mathrm{kg} /$ day while triangles denote animals given indomethacin, $10 \mathrm{mg} / \mathrm{kg} / \mathrm{day}$. The open figures are control animals (vehicle) while closed figures are experimental animals (captopril).
The $\mathrm{FE}_{\mathrm{pr}}$ was lower in captopril-treated rats compared to control counterparts in protocols I-III and V, although the difference was statistically significant only in protocol I $(0.022 \pm$ 0.004 , captopril-treated versus $0.035 \pm 0.005$, control; $p<0.03$ ). Of note was the similar degree of reduction in the $\mathrm{FE}_{\mathrm{pr}}$ achieved by captopril treatment in protocols I-III, i.e. $35 \% . \mathrm{FE}_{\mathrm{pr}}$ was the same in experimental $(0.008 \pm 0.003)$ and control animals $(0.009$ \pm 0.003 ) treated with indomethacin, $10 \mathrm{mg} / \mathrm{kg} \mathrm{BW} /$ day; moreover, in animals treated with indomethacin, $5 \mathrm{mg} / \mathrm{kg} \mathrm{BW} /$ day, the experimental group had a higher $\mathrm{FE}_{\mathrm{pr}}(0.033 \pm 0.01)$ compared to control animals $(0.020 \pm 0.004)$. Using the Duncan multiple range test, it was evident that the change in $F_{\mathrm{pr}}$ associated with captopril administration was significantly different in animals treated according to protocols IVA and IVB from those handled according to protocols I, II, and III. Thus, indomethacin abolished the similar reduction in $\mathrm{FE}_{\mathrm{pr}}$ achieved by captopril treatment in protocols I-III.

When samples of renal tissue were examined microscopically, all specimens showed fusion of epithelial cell foot processes and

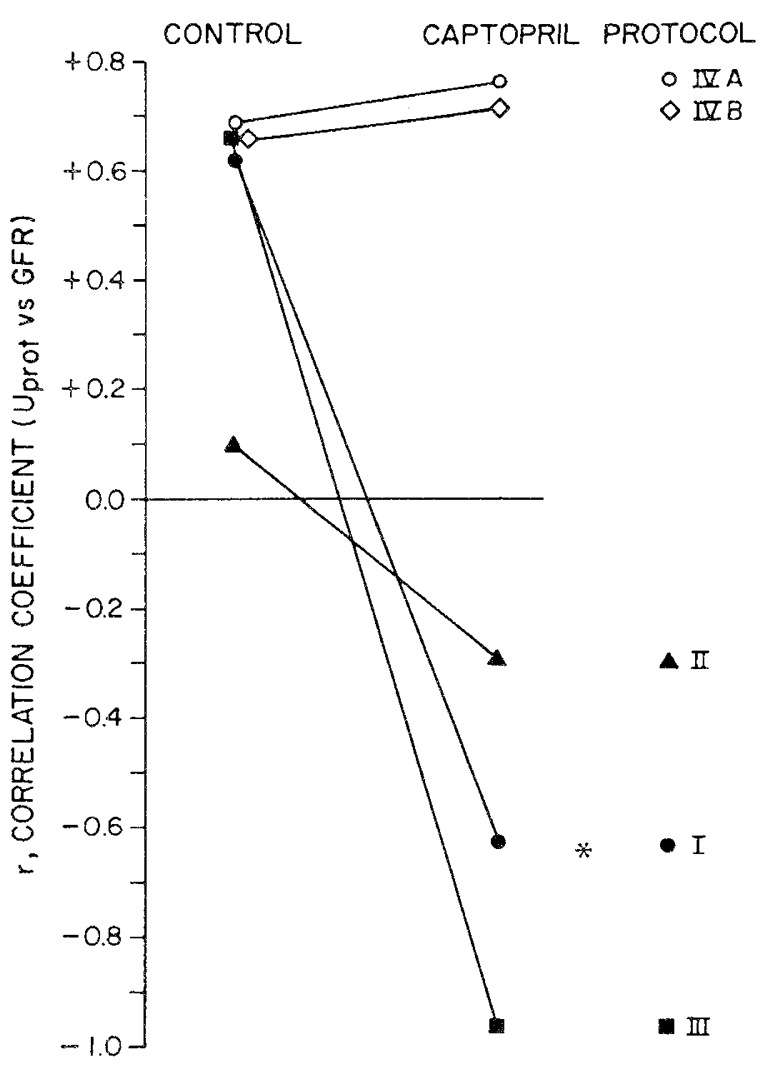

Fig. 6. Effect of captopril treatment on the correlation coefficient, $r$, relating urinary protein excretion (Uprot) versus GFR. ${ }^{*} p<0.05$. $\longrightarrow$ protocol I; $\longrightarrow$ protocol II; $\longrightarrow$ protocol III; $\bigcirc \quad \bigcirc$ protocol IVA; $\diamond \_\diamond$ protocol IVB.

Table 2. Renal function and urinary protein excretion on the final day of study in control and experimental animals, protocols $I-V$

\begin{tabular}{|c|c|c|c|c|c|c|}
\hline \multirow[b]{2}{*}{ Protocol } & \multicolumn{2}{|c|}{$\operatorname{Uprot}^{*}(\mathrm{mg} / 24 \mathrm{~h})$} & \multicolumn{2}{|c|}{ GFR (ml/min) } & \multicolumn{2}{|c|}{ FEpr } \\
\hline & $\mathrm{C}$ & $\mathrm{E}$ & $\mathrm{C}$ & $\mathrm{E}$ & $\mathrm{C}$ & $\mathrm{E}$ \\
\hline$I(n=9)$ & $136.0 \pm 13.1$ & $75.5 \pm 11.0 \dagger$ & $0.63 \pm 0.09$ & $0.75 \pm 0.11$ & $0.035 \pm 0.005$ & $0.022 \pm 0.004 \uparrow$ \\
\hline II $(n=5)$ & $71.9 \pm 14.3$ & $38.1 \pm 16.8$ & $0.55 \pm 0.08$ & $0.47 \pm 0.04$ & $0.013 \pm 0.003$ & $0.008 \pm 0.004$ \\
\hline III $(n=5)$ & $86.5 \pm 8.5$ & $48.9 \pm 9.8$ & $0.55 \pm 0.11$ & $0.76 \pm 0.24$ & $0.029 \pm 0.007$ & $0.019 \pm 0.003$ \\
\hline IVA $(n=5)$ & $62.7 \pm 8.1$ & $73.2 \pm 13.0$ & $0.43 \pm 0.06$ & $0.56 \pm 0.20$ & $0.020 \pm 0.004$ & $0.033 \pm 0.01$ \\
\hline $\operatorname{IVB}(n=5)$ & $16.8 \pm 6.4$ & $8.4 \pm 4.6$ & $0.39 \pm 0.07$ & $0.21 \pm 0.04$ & $0.009 \pm 0.003$ & $0.008 \pm 0.003$ \\
\hline $\mathrm{V}(n=4)$ & $169.3 \pm 7.2$ & $144.9 \pm 8.3$ & $1.26 \pm 0.12$ & $1.23 \pm 0.16$ & $0.035 \pm 0.003$ & $0.028 \pm 0.005$ \\
\hline
\end{tabular}

* Uprot, urinary protein excretion; C, control (vehicle); E, experimental (captopril).

Values reported as mean $\pm \mathrm{SEM} ; \dagger p 0.01 \mathrm{C}$ versus $\mathrm{E}$. 
increased cytoplasmic vacuolization. No differences were noted in the appearance of captopril-treated or control animals in any experimental protocol. Thus, PAN uniformly induced a nephrotic state in all of the experimental animals.

\section{DISCUSSION}

We have demonstrated that captopril, an orally active ACE inhibitor, is capable of effecting a $50 \%$ reduction in mean daily protein excretion in rats rendered nephrotic by the administration of PAN. This action was primarily a quantitative one and did not correct the underlying glomerular lesion since the degree of nephrosis was similar in all experimental and control animals. The inability of pharmacological doses of angiotensin II and aprotinin to diminish the efficacy of captopril in reducing protcinuria indicates that the drug acts via a pathway that is independent of AII or kinin production. In contrast, the administration of indomethacin abolished the captopril effect and implicates intrarenal prostaglandin synthesis and release as the primary mediator of the drug action.

The dose of captopril used in these experiments was consistent with that used in previous investigations studying its efficacy as a chronic antihypertensive agent $(12,14,15)$. At the dosage used in the present work, captopril is free of major toxic side effects. Moreover, although no blood pressure measurements are available, in the strain of rats used captopril does not exert any significant effect on systemic blood pressure (13-15). The doses of AII $(2,10,16,17)$, aprotinin $(10,18)$, and indomethacin $(19$, 20) used in this study are compatible with previously described usage, in the first instance, in both normal and nephrotic rats, and for the latter two drugs, in normal rats. In the case of aprotinin and indomethacin, they are associated with a substantial reduction in urinary kinin and prostaglandin excretion in normal rats $(10,18,19)$. Although the differential actions of AII, aprotinin, and indomethacin on renal hemodynamics are not well characterized in nephrotic animals, their administration was appropriately controlled in each experimental protocol. Thus, one must conclude that captopril treatment was responsible for the differences in urinary protein excretion observed in experimental versus control animals in protocol I-III and that indomethacin did, in fact, abolish the difference. However, it should be noted that although comparable data are lacking regarding prostaglandins and AII, urinary kallikrein excretion is decreased in nephrotic rats (21), so that captopril treatment may have affected blood pressure differently than expected in normal rats.

One other study in the literture has explored the effect of captopril on proteinuria in the spontancously hypertensive strain of rats with PAN nephrosis (22). The investigators concluded that captopril is unable to attenuate the proteinuria provoked by this nephrotoxic reagent. However, the experimental design utilized in this study was clearly different than ours since the daily urinary protein excretion was only measured until the initial, abrupt rise in PAN-induced proteinuria. We concur with the finding that captopril does not prevent the dramatic, early increase in protein excretion in response to PAN. However, if the animals are observed for an additional 7-day period, then a beneficial effect of captopril on PAN-induced proteinuria is clcarly demonstrable.

Table 3. Hemodynamic factors underlying the effects of vasoactive substances on urinary protein excretion

\begin{tabular}{|c|c|c|c|c|c|}
\hline & FEpr* & $\mathrm{Q}_{\mathrm{A}}$ & $k_{f}$ & $\Delta P$ & SNGFR \\
\hline $\begin{array}{l}\text { Vasoconstrictor substances, } \\
\text { c.g. All }\end{array}$ & $\uparrow$ & $\downarrow$ & $\downarrow$ & $\uparrow$ & $\leftrightarrow$ \\
\hline $\begin{array}{l}\text { Vasodilator substances. c..g. } \\
\text { PGE }_{1}\end{array}$ & $\downarrow$ & $\uparrow$ & $\downarrow$ & $\leftrightarrow$ & $\leftrightarrow$ \\
\hline
\end{tabular}

* FEpr, fractional excretion of protein: $Q_{A}$, renal blood flow; $k_{f}$ ultrafiltration coefficient: $\triangle \mathrm{P}$ hydrostatic pressure gradient; SNGFR, single nephron glomerular filtration rate.
The attenuation in proteinuria induced by captopril was not causally related to a direct effect on GFR. In protocols I-III, the captopril-treated animals had significantly lower levels of protein excretion than control rats despite comparable or even slightly higher values for GFR, unlike the case in protocol IVB in which high dose indomethacin drastically reduced the GFR and urinary protein excretion in tandem. However, this finding does not exclude the possibility that the captopril-induced changes in protein excretion were mediated via hormonal effects on hemodynamic factors (Table 3) (8). For example, Brenner and coworkers (2) have demonstrated that the augmentation of proteinuria induced by vasoconstrictor substances such as AII is a consequence of reductions in renal blood flow, $\mathrm{Q}_{\mathrm{A}}$ and ultrafiltration coefficient, $K_{f}$ and a balanced elevation in the hydrostatic pressure gradient, $\triangle \mathrm{P}$, without a change in GFR. In contrast, vasodilator substances such as kinins and prostaglandin $E_{1}$ may cause a reduction in the fractional excretion of protein with a near constancy of single nephron GFR as a result of an offsetting increase in $Q_{A}$ and a fall in $K_{f}(23)$.

The inability of an angiotensin infusion or aprotinin administration to abolish the captopril effect indicates that the drug is not acting via its inhibition of ACE to alter these glomerular hemodynamic factors. We postulate that the action of captopril in reducing protein excretion is, in all likelihood, mediated by increased prostaglandin synthesis and release, with consequent alterations in renal hemodynamics. Evidence in favor of this proposal is available from experiments using preparations of isolated glomeruli. In vitro cultures containing captopril and teprotide, directly and selectively, stimulated the glomerular synthesis and release of the vasodilatory prostanoids, prostaglandin $E_{2}$, and prostacyclin in the absence of AII or bradykinin (24). The hemodynamic changes induced by these prostaglandins are probably an increase in $\mathrm{Q}_{\mathrm{A}}$ and a concomitant fall in $\mathrm{k}_{\mathrm{f}}$. We do recognize that this functional explanation for the captoprilmediated reduction in urinary protein excretion is based on hemodynamic findings in normal rats and must be verified in the circumstance of nephrotic animals.

There has been much clinical investigation into the mechanism of action regarding the antihypertensive effect of captopril (2528 ). The consensus view is that the action of captopril in reducing blood pressure cannot be entirely explained by its inhibition of ACE. There is mounting evidence to suggest that captopriinduced changes in prostaglandin production can better account for the drug's antihypertensive action in essential hypertension $(26,28)$. Thus, the mechanism that we propose to explain the captopril attenuation in proteinuria in nephrotic rats is consonant with the pharmacological properties of the drug and the vascular response to its administration in a different setting. Moreover, the postulated hemodynamic changes involve known intrarenal actions of prostaglandins on $\mathrm{Q}_{\mathrm{A}}$ and $\mathrm{k}_{\mathrm{f}}(23)$.

Indirect evidence in favor of this hemodynamic mechanism of action for captopril may be gained by examining the drug effect in rats given adriamycin to induce nephrosis. Adriamycin causes proteinuria by altering the normal pore size distribution without affecting the GBM charge density $(29,30)$. This is in contrast to the well-studied effect of PAN which provokes proteinuria by depleting the glomerular capillary of its electronegative sialic acid residues $(31,32)$. Deen and Satvat (33) have demonstrated, using a mathematical model of macromolecular clearance, that the fracitonal excretion of protein is much more sensitive to alterations in $\mathrm{Cm}$, the glomerular capillary charge density, than to increases in the effective pore radius. If the action of PAN is to cause a $30 \%$ reduction in $\mathrm{cm}$ to $100 \mathrm{mEq} / \mathrm{liter}$, a change similar in magnitude to that observed in human minimal change disease (34), then alterations in $Q_{A}$ will still exert a significant effect on macromolecular clearance. These theoretical considerations might explain the failure of captopril to exert an effect in animals given adriamycin in comparison to the PAN nephrotic rats. It is also conceivable that captopril acts to replenish the GBM charge density in PAN-treated animals by donating 
its free sulfhydryl group. Such an effect would be consistent with previous work demonstrating inhibition by captopril of vascular permeability changes induced by histamine (35). It would explain the absence of any attenuation in proteinuria in rats given adriamycin. Future experiments including quantitative clearances of macromolecules of varying $\mathrm{pKa}$ and histochemical staining of the GBM with catatonic probes, will be needed to clarify whether captopril causes decreased proteinuria solely as a consequence of prostaglandin-mediated hemodynamic alterations or via a direct action on the GBM charge density.

It is important to note that under the experimental circumstances in which captopril was successful in decreasing proteinuria, it changed the correlation between daily protein excretion and GFR from a positive to a negative one. This relationship is important since it suggests that a similar inverse correlation will exist between urinary protein excretion and $Q_{A}$, since the latter is the major determinant of GFR. The administration of indomethacin abolished captopril's efficacy and restored a positive correlation between protein excretion and GFR. This agrees with prior investigations that described a direct GFR-dependent effect of indomethacin in reducing protein (4). These findings imply that when it is effective, the action of captopril was proportionately greater in animals with near normal levels of GFR. PAN, which is widely used to induce a model of nephrosis said to mimic human minimal change disease, is a nephrotoxic reagent that can cause progressive renal parenchymal injury (36-38). Since it is not possible to control the extent of renal damage induced by the PAN, it is conceivable that the treated animals represented a heterogeneous sample. The animals with less extensive PAN-induced injury to the kidney may have derived maximal benefit from captopril and demonstrated significant reduction in proteinuria, while the remaining animals with widespread glomerular sclerosis manifested minimal response to the drug. It will be necessary to perform further experiments in which animals are studied at vary times after the administration of PAN and in which the proteinuria is correlated with the histological findings to validate this speculation.

These findings offer the possibility of alternate modes of therapy for steroid-dependent or steroid-resistant forms of childhood minimal change nephrotic syndrome. Our results may also be relevant in early diabetic nephropathy which, like human minimal change disease, is characterized by depletion of GBM charge density $(34,39)$. Each of these glomerulopathies is marked, in its incipient stages, by a normal or elevated GFR so that the response to captopril might be anticipated to be maximal (40). Other agents, such as the calcium channel antagonists, may also be effective in reducing glomerular proteinuria by the same mechanism $(41,42)$. It remains to be proven whether the use of drugs such as captopril, which can reduce but not abolish urinary protein excretion, is able to arrest the progressive downhill course observed in many glomerular disorders. However, clinical data in patients with focal segmental glomerulosclerosis, indicating an accelerated rate of renal functional deterioration with increasing amounts of proteinuria, underscore the importance of therapeutic maneuvers that reduce proteinuria (43).

In summary, we have demonstrated that the administration of captopril to PAN-nephrotic rats causes a marked attenuation in the degree of proteinuria normally observed in these animals. The effect was preserved despite pharmacological doses of All or aprotinin but was abolished by the administration of indomethacin. We conclude that the action of captopril in reducing is probably mediated by alterations in renal hemodynamics, namely an increase in blood flow and a fall in the ultrafiltration coefficient, that are the consequence of increased intrarenal prostaglandin production.

Acknowledgments. The authors gratefully acknowledge the expert secretarial assistance of Ms. Katherine Balasis in the preparation of the manuscript. The captopril used in these experiments was kindly provided by Mr. Sol Lucania (E. R. Squibb
\& Sons, Inc.), the indomethacin by Frank J. Wolf, Ph.D. (Merck Sharp \& Dohme, Inc.), and the adriamycin by Ms. Kathleen Maglieri (Adria Laboratories, Inc.)

\section{REFERENCES}

1. Bauman JW Jr 1981 On the mechanism of angiotensin-induced proteinuria, 1. studies in aminonucleoside nephrotic rats and in Saralasin blockado. Nephron 27:47-50

2. Bohrer MP, Deen WM, Brenner BM 1977 Mechanism of angiotensin IIinduced proteinuria in the rat. Am J Physiol 233:F13-F21

3. Eisenbach GM, Van Liew JB, Boylan JW 1975 Effect of angiotensin on the filtration of protein in the rat kidney: a micropuncture study, Kidney Init 8:80-87

4. Arisz L, Donker AJM, Brentjens JRH, Van der Hem GK 1976 The effect of indomethacin on proteinuria and kidney function in the nephrotic symdrome. Acta Med Scand 199:121-128

5. Tiggeler RG WL, Hulme B, Wijdeveld PGAB 1979 Effect of indomethacin on glomerular permeability in the nephrotic syndrome. Kidney Int $16: 312-321$

6. Heel RC, Brogden RN, Spreight TM, Avery GS 1980 Captopril: a preliminary review of its pharmacological properties and therapeutic efficacy. Drugs 16:409-452

7. Murthy VS, Waldron TL, Goldberg ME 1978 The mechanism of bradykinin potentiation after inhibition of angiotensin-converting enzyme by SQ14225 in conscious rats. Circ Res 43(supp !):40-47

8. Dworkin LD, Ichikawa I, Brenner BM 1983 Hormonal modulation of glomerular filtration. Am J Physiol 244:F95-Fi04

9. Kanwar YS 1984 Biophysiology of glomerular filtration and proteinuria. Lab Inves! $51: 7-21$

10. Mimran A, Targhetta $R$, Laroche $B \quad 1980$ The antihypertensive effect of captopril: evidence for an influence of kinins. Hypertension 2:732-737

11. Kingsbury FB, Clark CP, Williams G, Post AL 1926 The rapid determination of albumin in urine. J Lab Clin Med 11:981-995

12. Arant BS Ir, Edelmann CM $\mathrm{J}$, Spitzer A 1972 The congruence of creatinine and inulin clearances in children: use of the Technicon Autoanalyzer. J Pediatr $81: 559-562$

13. Horovitz ZP, Rubin $\mathrm{B}$, Antonaccio MJ, Laffan RJ, High JP, Goldberg ME 1978 Antihypertensive effects of SQ14225, an orally active angiotensin Iconverting enzyme inhibitor, in spontaneously hypertensive rats (SHR) during chronic therapy. Fed Proc 37:718-725

14. Laffan RJ, Goldberg ME, High JP, Schaeffer TR, Waugh MH, Rubin B 1978 Antihypertensive activity in rats of SQ14225, an orally active inhibitor of angiotensin I-converting enzyme. J Pharmacol Exp Ther 204:281-288

15. Rubin B, Antonaccio MJ, Horovitz ZP 1978 Captopril (SQ14225) (D-3Mercapto-2-methylpropanoyl-L-proline): a novel orally active inhibitor of angiotensin-converting enzyme and antihypertensive agent. Prog Cardiovasc Dis 21:183-194

16. Textor SC, Brunner HR, Gavras H 1981 Converting enzyme inhibition during chronic angiotensin II infusion in rats: evidence against a nonangiotensin mechanism. Hypertension 3:269-276

17. Pernollet MG, Devynck MA, Matthews PG, Meyer P 1977 Post-nephrectomy changes in adrenal angiotensin II receptors in the rat: influence of exogenous angiotensin and a competitive inhibitor. Eur J Pharmacol 43:361-372

18. Trautschold I, Werle E, Zickgraf-Rudel G 1967 Trasylol. Biochem Pharmacol 16:59-68

19. Berl T, Aisenbrey GA, Linas SL 1980 Renal concentrating defect in the hypokalemic rat is prostaglandin independent. Am J Physiol 238:F37-F4I

20. Serros ER, Kirschenbaum MA 1981 Prostaglandin-dependent polyuria in hypercalcemia. Am J Physiol 241:F224-F230

21. Glasser RJ, Michael AF 1976 Urinary kallikrein in experimental renal disease. Lab Invest 34:616-622

22. Chiu PJS Brown AD 1981 Effect of captopril on pre-existing and aminonucleoside-induced proteinuria in spontaneously hypertensive rats. Res Commun Chem Pathol Pharmacol 31:419-433

23. Baylis C, Deen WM, Myers BD, Brenner BM 1976 Effects of some vasodilator drugs on transcapillary fluid exchange in renal cortex. Am $J$ Physiol $230: 1148-1158$

24. Galler M, Backenroth R, Folkert VW. SchlondorffD 1982 Effects of converting enzyme inhibitors on prostaglandin synthesis by isolated glomeruli and aortic strips from rats. J Pharmacol Exp Therap 220:23-28

25. Moore TJ, Crantz FR, Hollenberg NK, Koletsky RJ, Leboff MS, Swartz SL Levine L, Podolsky S, Dluhy RG, Williams GH 1981 Contribution of prostaglandins to the antihypertensive action of captopril in essential hypertension. Hypertension 3:168-173

26. Swartz SL, Williams GH, Hollenberg NK, Levine L, Dluhy RG, Moore TJ 1980 Captopril-induced changes in prostaglandin production: relationship to vascular responses in normal man. J Clin Invest 65:1257-1264

27. Vinci JM, Horwitz D, Zusman RM, Pisano JJ, Catt KJ, Keiser HR 1979 The effect of converting enzyme inhibition with SQ14225 on plasma and urinary kinins, prostaglandin $E$ and angiotensin II in hypertensive man. Hypertension 1:416-426

28. Zusman RM 1984 Renin-and non-renin-mediated antihypertensive actions of converting enzyme inhibitors. Kidney Int 25:969-983

29. Bertani T, Poggi A, Pozzoni R, Delaini F, Sacchi G, Thoua Y, Mecca C Remuzzi G, Donati MB 1982 Adriamycin-induced nephrotic syndrome in rats: Sequence of pathologic events. Lab Invest 46:16-23 
30. Weening JJ, Rennke HG 1983 Glomerular permeability and polyanion in adriamycin nephrosis in the rat. Kidney Int 24:152-159

31. Caulfield JP. Farquhar MG 1978 Loss of anionic sites from the glomerular basement membrane in aminonucleoside nephrosis. Lab Invest 39:505-512

32. Olson JL, Rennke HG, Venkatachalam MA 1981 Alterations in the charge and size selectivity barrier of the glomerular filter in aminonucleoside nephrosis in rats. Lab Invest $44: 271-279$

33. Deen WM, Satvat B 1981 Determinants of the glomerular filtration of proteins. Am J Physiol 241:F162-F170

34. Bridges CR, Myers BD, Brenner BM. Deen WM 1982 Glomerular charge alterations in human minimal change nephropathy. Kidney Int 22:677-684

35. Fantone JC, Schrier D, Weingarten B 1982 Inhibition of vascular permeability changes in rats by captopril. J Clin Invest 69:1207-1211

36. Blau EB, Michael AF 1972 Rat glomerular glycoprotein composition and metabolism in aminonucleoside nephrosis. Proc Soc Exp Biol Med 141:164172

37. Caulfield JP. Reid JJ. Farquhar MG 1976 Alterations of the glomerular epithelium in acute aminonucleoside nephrosis: evidence for formation of occluding junctions and epithelial cell detachment. Lab Invest 34:43-59 38. Glasser RJ, Velosa JA, Michael AF 1977 Experimental model of focal scierosis. I. Relationship to protein excretion in aminonucleoside nephrosis. Lab Invest 36:519-526

39. Christiansen JS, Gammelgaard J, Frandsen M, Parving HH 1981 Increased kidney size, glomerular filtration rate and renal plasma flow in short-term insulin-dependent diabetics. Diabetologia 20:451-456

40. De Bats A, Gordon AH, Rhodes EL 1974 Variation in glomerular sialic acid content in diabete and as a result of aging. Clin Sci Mol Med 47:93-95

41. Malis CD, Cheung JY, Leaf A, Bonventre JV 1983 Effects of verapamil in models of ischemic acute renal failure in the rat. Am J Physiol 245:F735F742

42. Wait RB, White G, Davis JH 1983 Beneficial effects of verapamil on postischemic renal failure. Surgery $94: 276-282$

43. Velosa JA, Holley KE, Torres VE, Offord KP 1983 Significance of proteinuria on the outcome of renal function in patients with focal segmental glomerulosclerosis. Mayo Clin Proc 58:568-577

\title{
Plasma Protease Inhibitors in $\alpha_{1}$-Antitrypsin- Deficient Children
}

\author{
TOMAS SVEGER \\ Departments of Pediatrics and of Clinical Chemistry, Malmö General Hospital, University of Lund, \\ Malmö, Sweden
}

\begin{abstract}
Seven plasma protease inhibitors were analyzed in 8-yr-old children-75 PiZ (severely deficient), one PiZ-(with a null gene), 32 PiSZ (moderately deficient), and 35 normals. In PiZ and PiSZ $\alpha_{1}$-antitrypsin-deficient children, significantly higher concentrations of $\alpha_{2}$-macroglobulin $(p<0.001)$ and antithrombin III $(p<0.001)$ were found and significantly lower concentrations of $\alpha_{2}-$ antiplasmin $(p<0.001)$, CI-inactivator $(p<0.01)$ and plasminogen (PiZ $p<0.02$, PiSZ $p<0.01$ ). The inter- $\alpha-$ trypsin inhibitor concentrations differed in PiSZ children only $(p<0.01)$. At this age the high $\alpha_{2}$-macroglobulin levels may be of importance to protect the lung tissue against free proteolytic activity, while importance of the other differences are unknown or reflect changes of purely theoretical interest. (Pediatr Res 19: 834-835, 1985)
\end{abstract}

\section{Abbreviations}

$\alpha_{1} \mathrm{AT}, \alpha_{1}$-antitrypsin

$\alpha_{1}$ ATD, $\alpha_{1}$-antitrypsin deficiency

$\alpha_{1} \mathrm{AC}, \alpha_{1}$-antichymotrypsin

$\alpha_{2} \mathbf{A P}, \alpha_{2}$-antiplasmin

$\alpha_{2} \mathrm{M}, \alpha_{2}$-macroglobulin

ATIII, antithrombin III

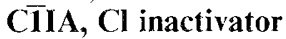

I- $\alpha$-I, inter- $\alpha$-trypsin inhibitor

PG, plasminogen

Reccived October 4, 1984: accepted March 26. 1985

Reprint requests Tomas Sveger, M.D. Department of Pediatrics, Malmö General Hospital. S-21401 Malmö. Sweden.
In $\alpha_{1}$ ATD, one important protease inhibitor is significantly reduced-in the PiZ state to $15 \%$ the PiSZ state to $40 \%$ and in the PIZ-state to $7.5 \%$ of the normal plasma level (1). Plasminogen and seven protease inhibitors- $\alpha_{1} \mathrm{AT}, \alpha_{2} \mathrm{M}, \alpha_{1} \mathrm{AC}, \alpha_{2} \mathrm{AP}, \mathrm{C} \overline{1} \mathrm{~A}$, ATIII, I- $\alpha$-I-were studied in 8 -yr-old children with $\alpha_{1}$ ATD followed prospectively since birth (2).

\section{MATERIALS AND METHODS}

EDTA-plasma (vacutainer) was drawn from $75 \mathrm{PiZ}$, one PiZ-, $32 \mathrm{PiSZ}$, and 35 age-matched control children. The age of both $\alpha_{1}$ ATD and control children was 8 yr 3 months \pm 3 months. All were apparently healthy and had normal blood cell counts and sedimentation rates. None had clinical signs of liver disease. Onethird of the PiZ, but none of the PiSZ children, had slightly increased plasma aminotransferase concentrations (2).

Plasma was stored at $-20^{\circ} \mathrm{C}$ until analyzed. Protein concentrations were determined by electroimmunoassay using antibodies available at the laboratory of clinical chemistry (3). The concentrations are given as percentages of Seronorm (batch 103), except that of ATIII for which a standard pool of blood-donor plasma (EDTA) is used. One hundred percent corresponds to $1.5 \mathrm{~g} \alpha_{1} \mathrm{AT} /$ liter, $2.5 \mathrm{~g} \alpha_{2} \mathrm{M} /$ liter; the Seronorm protein concentrations of the other inhibitors are not properly known.

\section{RESULTS}

The protease inhibitor concentrations of the 8-yr-old $\alpha_{1}$ ATD and control children are given in Table 1. $\alpha_{1}$ ATD children (both $\mathrm{PiZ}$ and SZ) had significantly higher concentrations of $\alpha_{2} \mathrm{M}$ ( $p$ 